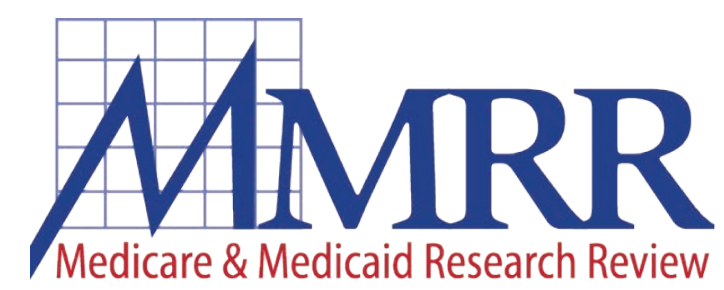

2014: Volume 4, Number 2

A publication of the Centers for Medicare \& Medicaid Services, Office of Information Products \& Data Analytics

\title{
What Influences the Awareness of Physician Quality Information? Implications for Medicare
}

\author{
Jon Christianson, ${ }^{1}$ Daniel Maeng, ${ }^{2}$ Jean Abraham, ${ }^{1}$ Dennis P. Scanlon, ${ }^{3}$ Jeffrey Alexander, ${ }^{4}$ \\ Jessica Mittler, ${ }^{3}$ and Michael Finch ${ }^{5}$ \\ ${ }^{1}$ University of Minnesota School of Public Health-Division of Health Policy and Management \\ ${ }^{2}$ Geisinger Health System-Center for Health Research \\ ${ }^{3}$ The Pennsylvania State University-Department of Health Policy \& Administration \\ ${ }^{4}$ University of Michigan-Health Management and Policy \\ ${ }^{5}$ Finch and King Consulting
}

Objective: Examine the factors that are associated with awareness of physician quality information (PQI) among older people with one or more chronic illnesses and the implications for Medicare.

Data Sources/Study Setting: Random digit-dial survey of adults with one or more chronic illnesses.

Research Design: Structural equation modeling to examine factors related to awareness of PQI.

Results: Awareness of PQI is low (13 percent), but comparable to findings in general population surveys. Age, race, education, and self-reported health status are associated with PQI awareness. Trust in the Internet as a source of health care information and not trusting one's physician as a source of information both are associated with a greater likelihood of being aware of PQI. Patients with high levels of activation have greater trust in physicians as information sources, but this is not associated with awareness, nor is degree of satisfaction with their care experience.
Conclusions: Awareness of PQI among older persons with chronic illnesses is relatively low across all socio-economic and demographic subgroups. Changes in population characteristics over time are unlikely to improve awareness in this population, nor are changes in patient activation or satisfaction with care. Medicare would need a broad-based effort if it wishes to raise PQI awareness among Medicare beneficiaries in the near term. Before undertaking resource-intensive efforts to increase awareness, Medicare may want to consider what level of awareness actually is needed to accomplish the overall objective for PQI transparency, which is raising the quality of care received by beneficiaries. It may be that relatively low levels of awareness are sufficient.

Keywords: awareness of physician quality measures, patient activation, public reporting, older persons, Medicare, chronic illness

ISSN: 2159-0354

doi: http://dx.doi.org/10.5600/mmrr.004.02.a02 


\section{Medicare \& Medicaid Research Review} 2014: Volume 4, Number 2

\section{Mission Statement}

Medicare \& Medicaid Research Review is a peerreviewed, online journal reporting data and research that informs current and future directions of the Medicare, Medicaid, and Children's Health Insurance programs. The journal seeks to examine and evaluate health care coverage, quality and access to care for beneficiaries, and payment for health services.

\section{http://www.cms.gov/MMRR/}

\section{U.S. Department of Health \& Human Services Kathleen Sebelius Secretary}

\section{Centers for Medicare \& Medicaid Services Marilyn Tavenner Administrator}

Editor-in-Chief

David M. Bott, Ph.D.

The complete list of Editorial Staff and Editorial Board members may be found on the MMRR Web site (click link): $\underline{\text { MMRR Editorial Staff Page }}$

Contact: $\underline{\text { mmrr-editors@cms.hhs.gov }}$

Published by the Centers for Medicare \& Medicaid Services.

All material in the Medicare \& Medicaid Research

Review is in the public domain and may be duplicated without permission. Citation to source is requested.

\section{Introduction}

In this article, we examine the factors that are associated with awareness of physician quality information (PQI) among older people with one or more chronic illnesses. Making physician quality differences more transparent could improve quality of care by leading consumers to choose higher quality physicians, enhancing the quality of their interactions with physicians, or stimulating quality improvement on the part of physicians to avoid loss of patients and the stigma associated with low quality scores (Mehrotra, Hussey, Milstein, \& Hibbard, 2012).

The reporting of health plan and hospital quality information began in the early 1990s and has recently expanded, with the support of large employers, to include measures of physician performance (Christianson, Ginsburg, \& Draper, 2008). The Robert Wood Johnson Foundation has encouraged physician performance reporting through its Aligning Forces for Quality initiative (AF4Q), and health insurers now routinely provide PQI to members (Christianson, Volmar, Shaw, \& Scanlon, 2012). Medicare's Physician Compare effort provides beneficiaries with information on physician characteristics, with patient assessments of care and clinical quality measures expected by 2015 (Millenson, 2011). In addition, health reform legislation requires CMS to share Medicare data with "qualified" local entities for their use in public reporting of PQI (Centers for Medicare \& Medicaid Services, 2012), and there is support for public reporting of physician quality on health insurance exchanges (Consumer-Purchaser Disclosure Project, 2013).

Prior to these efforts, Harris and Buntin (2008) observed that "...awareness of publicly available information is low in the general population and 
among patients with high health needs for whom the information should be most relevant" (p. 7), with about 12 percent of the general population reporting seeing PQI. Different explanations have been offered for this low level of awareness. For example, relatively healthy people may not be motivated to seek out PQI because they use medical care only sporadically. Another possible explanation is that consumers trust traditional sources of information on PQI, such as family members and friends, or their own physicians, and therefore have little reason to look elsewhere. Or, if consumers lack confidence in their ability to successfully locate and act on PQI, they may chose not to search, or they may search ineffectively. Finally, some consumers may not be aware of PQI because little is available or it is not disseminated effectively.

Where publicreports are available, they typically contain measures of the quality of chronic illness care (Christianson, Volmar, Alexander, \& Scanlon, 2010). About two-thirds of Medicare beneficiaries have 2 or more chronic conditions, with the number of conditions increasing with age, and beneficiaries with more chronic conditions have more physician office visits annually (Centers for Medicare \& Medicaid Services, 2012). This suggests that PQI could be of use to Medicare beneficiaries if they were aware of it. However, even people with chronic health problems may lack motivation to search for PQI if their frequent contact with physicians creates opportunities for them to reach their own conclusions about physician performance, or creates a sense of loyalty.

We were able to locate only two studies in the peer-reviewed literature that examined factors influencing awareness of PQI (Abraham, Feldman, \& Carlin, 2004; Abraham, Feldman, Carlin, \& Christianson, 2006). These studies found that more aggressive employer information dissemination was associated with greater awareness, and that females and people at higher education levels were more likely to be aware, as were individuals who had a chronic illness (Abraham et al., 2006). However, study participants consisted entirely of employees of large employers in a single metropolitan area. Information in the reports reflected primarily employee self-reported experience in care systems, and experience was reported at the "care system" level, rather than the physician practice or group level. At that time, there were no other reports of physician performance available to community residents.

In this article, we address awareness of PQI generally, as opposed to awareness of a particular employer-distributed report. The use of the Internet to disseminate all types of information, including health-related information, has grown substantially in recent years, which makes our findings more relevant to the current environment, and we focus on the relative importance of factors that are associated with awareness of PQI among persons 65 years of age and older with one or more chronic conditions, increasing the usefulness of the study results for Medicare. We discuss the implications of our findings for Medicare and its planned PQI reporting efforts.

\section{Conceptual Framework}

We expect that awareness of PQI will depend on the level of search activity as well as the availability of PQI in the environment. While we do not measure search activity directly, consistent with past research we examine relationships between exogenous factors that are expected to be related to search activity (such as demographic and socio-economic characteristics and illness burden) and therefore awareness of PQI. In addition, we hypothesize that these exogenous factors could influence awareness through their relationships to trust in alternative information sources, consumer confidence in ability to search for and act on PQI, and satisfaction with current care experience. Each of these three constructs could have an independent effect on awareness as well, and there may be associations among them (Exhibit 1). 


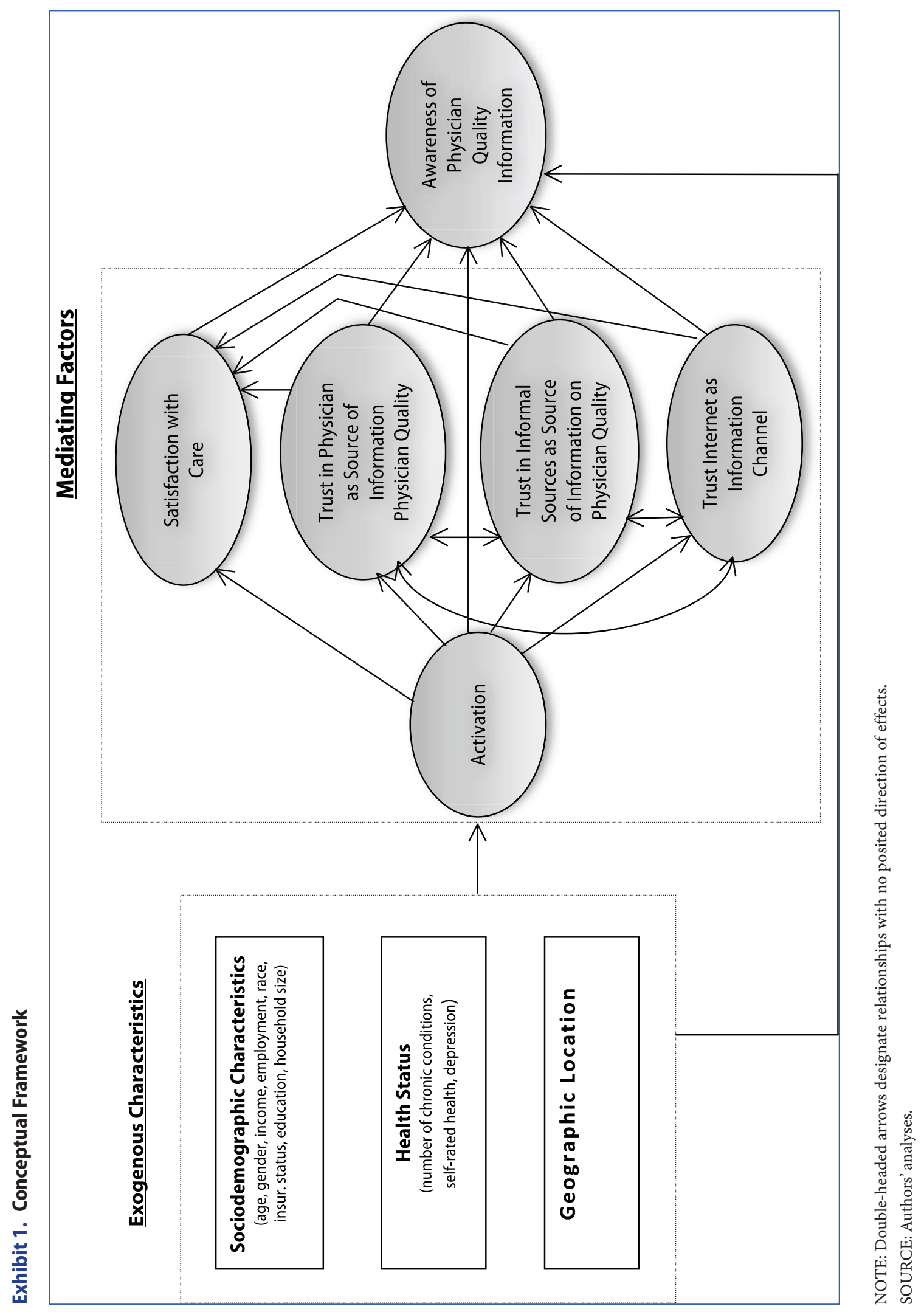




\section{Exogenous factors}

\section{Demographic and socioeconomic characteristics}

We expect that awareness of PQI will be related to demographic and socio-economic characteristics of individuals, consistent with findings from the two previous studies of factors influencing awareness of PQI, studies of awareness of health plan and hospital comparative quality data (Kolstad \& Chernew, 2009; Scanlon \& Chernew, 1999; Harris \& Buntin, 2008; Schneider \& Epstein, 1998), and studies of the determinants of information searches for non-health care related goods (e.g., Klein \& Ford, 2002). While our study focuses on people 65 years of age and older, some study participants received health insurance coverage through an employer or by purchasing supplemental Medicare insurance from private health insurers. We expect that people with private insurance of any sort will be more likely to be aware of PQI due to the dissemination efforts of health plans and employers.

\section{Health status}

We expect that people with poorer health status will have a greater desire for information to help them manage their care and will more actively search for information; consequently, they will be more likely to be aware of PQI. Another possibility is that they will develop greater confidence in their own assessment of quality through frequent contact with their physicians and have fewer reasons to search for PQI from formal sources. (Chronic illness care may be an "experience good" with consumers accumulating evidence on quality through repeat purchases of physician services.) People with depression also may be less likely to search for information, due to lower levels of motivation.

\section{Geographic location}

The number of reports of PQI and how the existence of reports is communicated vary across communities (Christianson et al., 2010). In some communities, it simply may be easier for consumers to find PQI, and the availability of physician alternatives for consumers also could vary by location, affecting the motivation of consumers to search for PQI.

\section{Mediating Factors}

\section{Level of Activation}

Searching for PQI can be seen as a "self-management" behavior on the part of people with chronic illnesses (Hibbard, 2009). There is a growing literature on the relationship between "patient activation" and self-management behaviors (Hibbard \& Greene, 2013). In this literature, "activation" is defined as “...understanding one's role in the care process and having the knowledge, skill, and confidence to manage one's health and healthcare" (Hibbard \& Greene, 2013, p. 207), and "degree of activation" is assessed using a Patient Activation Measure (PAM). Four stages of activation are identified: Stage 1, patient believes an active role is important; stage 2, patient has confidence and knowledge to take action; Stage 3, patient takes action; and Stage 4, patient stays the course under duress (Hibbard, Mahoney, Stockard, \& Tusler, 2005). Highly activated patients (stage 4) are thought to be more likely to carry out "consumeristic" behaviors, such as searching for health information and using that information in decision-making. While this suggests that a higher level of activation will be associated with a greater likelihood of being aware of PQI, it is also plausible that activated consumers possess greater confidence in their ability to judge quality based on their own experience; therefore, they will be less likely to seek out PQI and, all else equal, less likely to be aware of it. We found no studies that examined the relationship between patient activation and awareness of PQI.

\section{Satisfaction with Current Care}

We expect that individuals who are highly satisfied with their current care will see less need to search 
for PQI; therefore, they will be less likely to be aware of it. We also expect that highly activated consumers will be more successful at "matching" with providers who meet their needs, so that higher levels of activation will be associated with higher levels of satisfaction.

\section{Trust in Information Sources}

Recent research suggests that people with chronic illnesses trust information provided by hospitals and physicians more than information provided by informal sources, such as family and friends, or more formal sources, such as health plans and government (Alexander, Hearld, Hasnain-Wynia, Christianson, \& Martsolf, 2011). We expect that individuals who place greater trust in physicians or in family and friends as sources of quality information will be less likely to search for PQI and to be aware of it.

Internet Web sites are the primary means for disseminating PQI. We hypothesize that people who place the greatest trust in the Internet as an information source will be more likely to turn to it when seeking information on physician quality; therefore, they will have a relatively high awareness of PQI. More activated consumers may have greater confidence in their ability to assess the credibility of information found on the Internet; therefore, they may place greater trust in it as an information channel.

\section{Data}

Our exploratory analysis uses data from a random digit dial telephone survey undertaken as part of the evaluation of the AF4Q initiative. The survey was administered between June 2007 and June 2008 to adults living in 14 geographic areas as well as to a supplementary sample drawn randomly from the rest of the United States. Eligibility required that individuals have asthma, diabetes, hypertension, coronary artery disease, and/or depression, as determined in a screener interview (survey details can be found in Scanlon et al., 2012.).

The overall survey response rate was 27 percent using the American Association of Public Opinion Research methodology and 48 percent using Council of American Survey Research Organizations methodology. These are comparable to rates reported by others (e.g., Couper et al., 2010) for random digit dial surveys of the general population during the same time period. Their surveys did not include screener interviews, which could have had a negative effect on response rates in the AF4Q survey. The possibility of non-response bias in the AF4Q survey was addressed by comparing respondent characteristics to respondents age 65 and older with chronic illness who took part in the in-person household survey conducted by the National Health Interview Survey (NHIS). The response rate is $90 \%$ in the NHIS, so its respondents are likely to be representative of people in the United States with the identified chronic illnesses. Respondents in the AF4Q survey were comparable to those in the NHIS with respect to demographic characteristics.

Awareness of PQI was assessed by using two sequential survey questions: First, "In the past twelve months, do you remember seeing any information comparing different doctors, hospitals, or health plans" and second, "Did you see any information comparing the quality among different doctors in the past 12 months". This second question was asked of those who responded "yes" to the first question. Thirteen percent of individuals 65 years of age and older responded positively to both questions, indicating that they had seen comparative PQI. (The same level of awareness was reported by respondents under 65 years of age.)

There were 2,834 individuals 65 and older who responded to these survey questions. There 
were no missing responses for the exogenous factors, but sixty-four respondents had missing data pertaining to one or more of the mediating factors. They were excluded from the analysis, resulting in an analytic sample of 2,770 individuals aged 65 and older.

\section{Methodology}

We used structural equation modeling (SEM) to estimate the relationships in our model (for an example of how this approach has been used by others to address health care questions, see Lee \& Lin, 2010). SEM allows us to explicitly examine the mediating effects of variables on awareness of PQI (Baron \& Kenny, 1986). The software used for estimation was LISREL ( $v$ 8.80). We label the exogenous variables $\xi i$, for person $i$, and the vector of endogenous factors $\eta i$. Thus, the estimation model is:

$$
\eta=\alpha+B \eta+\Gamma \xi+\zeta
$$

where $\boldsymbol{\eta}$ is an $m \times 1$ vector consisting of the dependent variable (awareness of PQI) and the mediating factors (level of activation, satisfaction with current care, trust in information sources), and where it is assumed that there is an $n \times 1$ vector $\xi$ of exogenous variables (e.g., age, gender), and that the $m \times 1$ vector $\zeta$ of error terms has a zero mean and covariance matrix $\Psi$, and $\operatorname{cov}\left(\xi, \zeta^{\prime}\right)$ $=\mathbf{0}$. Because the model is recursive and all the variables in the model are observed, estimation of coefficients reduces to a just-identified path analysis. Standardized coefficients are reported to remove effects of scaling. Standardized coefficients refer to how many standard deviations in awareness or mediating variables are associated with a standard deviation change in an exogenous or mediating variable.

\section{Descriptive Results}

Older, non-White, and more educated respondents were more likely to be aware of PQI, as were those with private insurance. Regarding respondent health status, individuals who self-reported poorer health or more chronic conditions were more likely to be aware of PQI, and people with depression were less likely to be aware. Among the mediating variables with categorical responses, people expressing a great degree of trust in the Internet had a greater likelihood of being aware of PQI, but relatively few respondents (6\%) said they "trusted the Internet a lot" as a source of PQI. Individuals at PAM level 4 exhibited a higher level of awareness compared to individuals at lower PAM levels (Exhibit 2).

Overall, differences in awareness across categories pertaining to a specific personal characteristic were relatively small. Differences across locations were larger, ranging from $10-20 \%$ in metropolitan areas (not shown). This could reflect differences in availability of PQI, or differences in relative aggressiveness of PQI dissemination. Communities with higher levels of awareness were not necessarily communities where reports produced by local coalitions had been available the longest.

\section{Structural Equations Results}

In estimating the structural equation model, the referent category for all three "trust variables," was the middle response, "trust a little." Overall, the R-squared for the estimated model is significant, but it explains only 3 percent of the variation in awareness.

\section{Exogenous Characteristics}

People with a higher level of education were more likely to be aware of PQI, consistent with findings 
Exhibit 2. Descriptive Statistics: Awareness of Physician Quality Information

\begin{tabular}{|c|c|c|c|}
\hline & Mean & SD & $\%$ Aware \\
\hline \multicolumn{4}{|l|}{ Awareness of Physician Quality Information } \\
\hline Among People 65 Years and Older with One or & 0.13 & 0.33 & 12.60 \\
\hline \multicolumn{4}{|l|}{ More Chronic Illnesses (in past 12 months) } \\
\hline \multicolumn{4}{|l|}{ 1. Sociodemographic Characteristics } \\
\hline \multicolumn{4}{|l|}{ Age $^{\star}$} \\
\hline Age Category: $65-74$ & (referent) & & 11.57 \\
\hline Age Category: 75+ & 0.46 & 0.50 & 13.74 \\
\hline \multicolumn{4}{|l|}{ Gender } \\
\hline Male & (referent) & & 12.10 \\
\hline Female & 0.69 & 0.46 & 12.77 \\
\hline \multicolumn{4}{|l|}{ Race/Ethnicity/Language ${ }^{* * *}$} \\
\hline White & (referent) & & 11.21 \\
\hline Black & 0.23 & 0.42 & 16.30 \\
\hline Other Race & 0.05 & 0.22 & 16.20 \\
\hline \multicolumn{4}{|l|}{ Family Structure } \\
\hline Household Size $=1$ & (referent) & & 12.24 \\
\hline Household Size $=2$ & 0.43 & 0.50 & 12.49 \\
\hline Household Size $=3$ or more & 0.09 & 0.29 & 14.45 \\
\hline \multicolumn{4}{|l|}{ Employment } \\
\hline Unemployed or Other & (referent) & & 12.66 \\
\hline Employed Full or Part-Time & 0.10 & 0.31 & 11.72 \\
\hline \multicolumn{4}{|l|}{ Insurance Status ${ }^{\star *}$} \\
\hline Does Not Have Private Health Insurance & (referent) & & 10.17 \\
\hline Has Private Health Insurance & 0.75 & 0.43 & 13.37 \\
\hline \multicolumn{4}{|l|}{ Education ${ }^{\star}$} \\
\hline Less than HS / HS Graduate & (referent) & & 12.42 \\
\hline Associate Degree & 0.17 & 0.37 & 10.13 \\
\hline Bachelor's Degree & 0.14 & 0.35 & 13.17 \\
\hline Master's / Doctorial Degree & 0.11 & 0.32 & 16.61 \\
\hline \multicolumn{4}{|l|}{ 2. Health Status } \\
\hline \multicolumn{4}{|l|}{ Self-Rated Health ${ }^{\star \star}$} \\
\hline Health Status: Poor / Fair & (referent) & & 14.97 \\
\hline Health Status: Good & 0.40 & 0.49 & 12.06 \\
\hline Health Status: Very Good / Excellent & 0.27 & 0.44 & 10.60 \\
\hline \multicolumn{4}{|l|}{ Self-reported Depression } \\
\hline No Depression & (referent) & & 12.92 \\
\hline Has Depression & 0.11 & 0.32 & 9.78 \\
\hline
\end{tabular}


Exhibit 2 Continued. Descriptive Statistics: Awareness of Physician Quality Information

\begin{tabular}{|c|c|c|c|}
\hline & Mean & SD & \% Aware \\
\hline \multicolumn{4}{|l|}{ Number of Chronic Conditions } \\
\hline 1 Chronic Condition & (referent) & & 12.06 \\
\hline 2 Chronic Conditions & 0.34 & 0.47 & 12.34 \\
\hline 3+ Chronic Conditions & 0.13 & 0.34 & 15.09 \\
\hline \multicolumn{4}{|l|}{ 3. Mediating Variables } \\
\hline \multicolumn{4}{|l|}{ Satisfaction with Care Experience } \\
\hline Satisfaction rating of Providers ( $0-10$ scale) & 8.87 & 1.54 & \\
\hline \multicolumn{4}{|c|}{ Trust in information from your doctor about health care quality provided by doctors } \\
\hline Not at all & (referent) & & 20.00 \\
\hline A little & 0.10 & 0.30 & 13.78 \\
\hline A lot & 0.88 & 0.33 & 12.27 \\
\hline
\end{tabular}

Trust in information from family, friends or coworkers on health care quality provided by doctors

$\begin{array}{lccr}\text { Not at all } & \text { (referent) } & 10.44 \\ \text { A little } & 0.51 & 0.50 & 12.88 \\ \text { A lot } & 0.36 & 0.48 & 12.37\end{array}$

Trust internet as source of health care quality provided by doctors ${ }^{* *}$

Not at all

A little

A lot

Activation Level ${ }^{\star *}$

PAM Stage 1

PAM Stage 2

PAM Stage 3

PAM Stage 4

NOTES:

$*$ = significant at .10 level

$* *=$ significant at .05 level

$* * *=$ significant at .01 level

SOURCE: Authors' analyses.

from past research. There was a direct effect of this variable on awareness as well as a reinforcing indirect effect on awareness through the mediating variables (Exhibit 3). The difference between having a masters or doctoral degree versus a high school education or less was equal to .053 standard deviations. People 75 years and older were more likely to report being aware of PQI controlling for other factors. This is consistent with prior results that length of residence in a community (referent)

11.61

$0.34 \quad 0.47 \quad 13.12$

$0.06 \quad 0.23$

19.26

(referent)

12.21

0.19

0.39

10.31

0.41

0.49

11.66

0.36

0.48

14.80 is positively related to awareness (Abraham et al., 2006). The negative indirect effect is primarily the result of a negative relationship between being 75 years or older and trusting the Internet "a lot."

People with self-reported better health status were less likely to be aware of PQI, consistent with the expectation that they would see less need to search for PQI. Having private insurance increased the likelihood of awareness, supporting the hypothesis that PQI is more readily accessible for people with 
Exhibit 3. Direct and Indirect Effects of Exogenous Variables on Awareness of Physician Quality Information

\begin{tabular}{|c|c|c|}
\hline & Direct & Indirect \\
\hline Greater than or equal to 75 years & $.049^{* *}$ & $-.013^{\star \star *}$ \\
\hline Race-Black & $.046^{* *}$ & NS \\
\hline Race-Other & $.036^{\star}$ & NS \\
\hline $\begin{array}{l}\text { Has private insurance } \\
\text { (referent: no private insurance) }\end{array}$ & $.041^{* *}$ & NS \\
\hline $\begin{array}{l}\text { Masters or doctoral degree } \\
\text { (referent: high school or less) }\end{array}$ & $.041^{* *}$ & $.012^{\star * *}$ \\
\hline $\begin{array}{l}\text { Self-rated health status- } \\
\text { very good or excellent (referent: poor) }\end{array}$ & $-.056^{\star *}$ & NS \\
\hline
\end{tabular}

private insurance. Non-White individuals were more likely to be aware of PQI. The estimated direct effects for race, health status, and private insurance were not modified by indirect effects operating through any of the mediating variables.

\section{Mediating Variables}

Exhibit 4 displays significant direct and indirect pathways through which the mediating variables affect awareness of PQI. While "trust in informal sources" was included in the statistical model, it was not significantly related to awareness or any of the other mediating variables, so was excluded from Exhibit 4.

We found no significant direct or indirect associations between PAM levels and PQI awareness. This does not support the expectation that higher activated consumers are more likely to perform "consumeristic" behaviors (Hibbard, 2009), but is consistent with research suggesting that improvements in PAM scores do not increase the likelihood that patients know where to find information that compares hospital quality (Harvey, Fowles, Xi, \& Terry, 2012). PAM levels 3 and 4 were positively associated with "trust in physician a lot" as a source of information, suggesting that more activated consumers are more likely to "match" with physicians they trust; and, PAM levels 2, 3, and 4 were positively associated with "satisfaction with care," consistent with the expectation that more activated consumers will be more aggressive in finding physicians who meet their expectations. However, neither "trust in physician a lot" nor "satisfaction with care" were related to awareness. Trust in the Internet "a lot" was positively associated with awareness, as was "trust physician not at all." However, as shown in the descriptive statistics presented in Exhibit 2, only a relatively small proportion of respondents were in each of these categories, suggesting that while statistically significant, the practical importance of these results may be limited.

\section{Discussion}

Medicare's Physician Compare Web site soon will provide beneficiaries and participating physicians with comparative physician quality information. Several of the specific findings from our exploratory analysis have potential implications for this effort. First, in almost all 


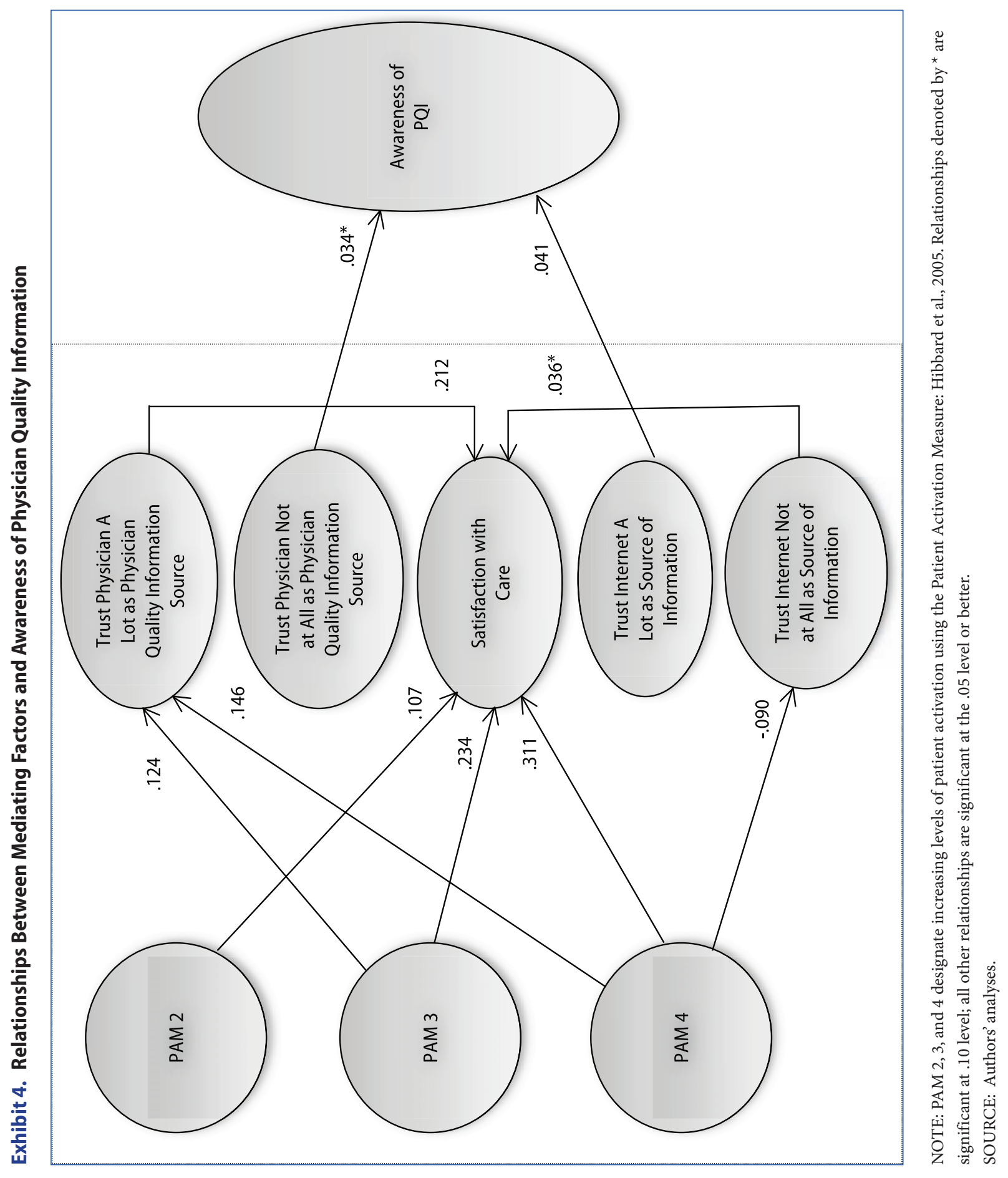


cases where there were statistically-significant relationships between exogenous variables and awareness, the absolute differences in awareness across categories of individual characteristics (e.g., 65-74 years of age versus 75+) were relatively small. Consequently, low overall awareness is not due to very low awareness in specific subgroups, and closing the gaps in awareness across categories within subgroups would not raise overall awareness appreciably. For example, if all respondents were at the educational level of master's degree or above, awareness would increase from 12.6 percent to 16.5 percent. Unfortunately, according to census figures, the population $65-74$ years of age with advanced degrees increased at an average annual rate of only .4 percent from 2000 to 2010 .

These observations suggest that Medicare would need a broad-based effort if it wishes to raise PQI awareness among beneficiaries in the near term. This presents a familiar challenge for Medicare, as past studies have reported low levels of understanding among Medicare beneficiaries of basic features of Medicare (Gold, Sinclair, Cahill, Justh, \& Mittler, 2001). In assessing barriers confronted by Medicare when implementing its Medicare+Choice program, Stevens and Mittler (2000) observed that "....getting information across to beneficiaries is hard," and "...education takes time and money" (p. xix), cautioning that "Policymakers need to have realistic expectations of what education can do and the limits of even the most successful education program" (p. xx). In effect, to raise PQI awareness among beneficiaries, Medicare would need to create a demand for PQI among people who do not know it exists and who generally trust the information sources they currently use. For Medicare, this task is complicated by the fact that about a quarter of beneficiaries have cognitive impairments, and over a third have low levels of literacy (Stevens \& Mittler, 2000).
Before undertaking such an effort, Medicare may want to consider what level of awareness is likely to be "enough" to accomplish the overall objective for PQI transparency - raising the quality of care received by beneficiaries. The actions of even a small minority of aggressive, informed consumers may be sufficient to generate market improvements that benefit all (Beales \& Salop, 1980). In our study, respondents who were highly educated and in poorer health were more likely to be aware of PQI. Future research should address the question of what proportion of consumers, and with what characteristics, need to be aware of PQI to improve quality through physician selection or enhanced interactions with physicians, or by stimulating physicians to improve their quality in order to protect their reputations.

There is at least some preliminary evidence that such questions are worth exploring. For instance, the AF4Q survey used in our research contained respondents from the State of Wisconsin, only eleven percent of whom reported awareness of PQI despite the fact that a local health care coalition was disseminating PQI reports. Nevertheless, Smith, Wright, Queram, and Lamb (2012) found that public reporting in Wisconsin was an important driver of physician practice efforts to improve their performance. (The study did not address actual improvement in quality of care.) These findings add to a growing perception that physicians will respond to PQI reports by attempting to improve quality of care, even when awareness among consumers is limited.

\section{Limitations}

There are several limitations in our study. First, we use a general measure of PQI awareness and examine factors that are associated with general awareness. Future research should address factors 
that affect awareness of the PQI on Medicare's Web site. Second, survey respondents were asked if they had seen comparative information in the last 12 months. Had a longer recall period been used, the percentage of respondents reporting awareness would have been higher, and results concerning factors related to awareness might have been different. However, the 12 month recall period seems appropriate for this analysis because of the focus on people with chronic illness who have frequent contact with the health care system. Third, there may be relevant factors related to awareness that were not included in this exploratory analysis. While we were constrained to measures that could be constructed from the AF4Q survey, it seems likely that any omitted characteristics would be highly correlated with those included in our analysis.

We focused only on factors related to PQI awareness, which we believe is appropriate given the significance of the issue and the lack of research related to it. However, equally little is known regarding use of PQI among persons who are aware of it (Harris \& Buntin, 2008). Our analysis also was limited in scope by our use of indicator variables for region of respondent residence to control for geographic influences on awareness. Future analyses might use specific geographic descriptors in place of indicator variables. Finally, we estimated our model using cross-sectional data; longitudinal survey data would allow testing of causal hypotheses relating to the factors affecting PQI awareness.

\section{Conclusions}

We examined factors that are associated with awareness of PQI using cross-sectional survey data gathered from people 65 years and older with chronic illnesses. We found that current awareness is low in this population and that increasing awareness through targeted programmatic efforts would be challenging for Medicare. The justification for devoting resources to more ambitious efforts that would raise awareness of PQI across all Medicare beneficiaries requires a clearer understanding of the level of beneficiary awareness needed to accomplish the ultimate goal for transparent PQI, which is better quality of care for consumers.

\section{Correspondence}

Jon Christianson, Ph.D., Division of Health Policy and Management, University of Minnesota School of Public Health, 420 Delaware Street SE, MMC 729, Minneapolis, MN 55455, chris001@umn.edu, Tel. (612) 625-3849, Fax. (612) 624-2196

\section{Financial Disclosure}

This research was supported by a grant from the Robert Wood Johnson Foundation for the evaluation of its Aligning Forces for Quality Initiative.

\section{References}

Abraham, J., Feldman, R., \& Carlin, C. (2004). Understanding employee awareness of health care quality information: how can employers benefit? Health Services Research, 39(6 Pt. 1), 1799-1816. PubMed http://dx.doi.org/10.1111/ j.1475-6773.2004.00319.x

Abraham, J. M., Feldman, R., Carlin, C., \& Christianson. J. (2006). The effect of quality information on consumer health plan switching: evidence from the Buyers Health Care Action Group. Journal of Health Economics, 25(4), 762-781.

Alexander, J. A., Hearld, L. R., Hasnain-Wynia, R., Christianson, J. B., \& Martsolf, G. R. (2011). Consumer trust in sources of physician quality information. Medical Care Research and Review, 68(4), 421-440. 
Baron, R. M., \& Kenny, D. A. (1986). The moderator-mediator variable distinction in social psychological research: Conceptual, strategic, and statistical considerations. Journal of Personality and Social Psychology, 51(6), 11731182. PubMed http://dx.doi.org/10.1037/00223514.51.6.1173

Beales, H. \& Salop, S. (1980). Selling consumer information. NA-. Advances in Consumer Research. Association for Consumer Research (U. S.), 7, 238-240.

Centers for Medicare \& Medicaid Services (2012). Medicare continues effort to give consumers more information on health care quality [press release]. Retrieved from http://www.cms.gov/ apps/media/press/release.asp?Counter $=4483 \&$ i ntNumPerPage $=10 \& \operatorname{checkDate}=\& \operatorname{checkKey}=\&$ srchType $=1 \&$ numDays $=3500 \&$ srchOpt $=0 \& s r c$ $\mathrm{hData}=\&$ keywordType $=$ All $\&$ chkNewsType $=1 \%$ $2 \mathrm{C}+2 \% 2 \mathrm{C}+3 \% 2 \mathrm{C}+4 \% 2 \mathrm{C}+5$ \&intPage $=$ \&showAl $\mathrm{l}=\& \mathrm{p}$ Year $=\& y e a r=\& d e s c=$ false $\&$ cboOrder $=$ date

Christianson, J. B., Ginsburg, P., \& Draper, D. (2008). The transition from managed care to consumerism: a community-level status report. Health Affairs, 27(5), 1362-1370. PubMed http:// dx.doi.org/10.1377/hlthaff.27.5.1362

Christianson, J. B., Volmar, K. M., Alexander, J., \& Scanlon, D. P. (2010). A report card on provider report cards: current status of the health care transparency movement. Journal of General Internal Medicine, 25(11), 1235-1241.

Christianson, J. B., Volmar, K. M., Shaw, B. W., \& Scanlon, D. B. (2012). Producing public reports of physician quality at the community level: the aligning forces for quality initiative experience. The American Journal of Managed Care, 18(6), S133-S140. PubMed
Consumer-Purchaser Disclosure Project. (2013). Letter to Rebecca Zimmerman, Centers for Medicare \& Medicaid Services. Ref.: CMS-9962-NC: RFI regarding health plan quality management in affordable insurance exchanges.

Couper, M. P., Singer, E., Levin, C. A., Fowler, F. J., Fagerlin, A., \& Zikmund-Fisher, B. J. (2010). Use of the internet and ratings for information sources for medical decisions: results from the DECISIONS survey. Medical Decision Making, 30(5 Suppl), 106S-114S.

Gold, M., Sinclair, M., Cahill, M., Justh, N., \& Mittler, J. (2001). Medicare beneficiaries and health plan choice, 2000. Executive Summary. Washington, DC: Mathematica Policy Research, Inc. MPH Reference No. 8604-200.

Harris, K. M. \& Buntin, M. B. (2008). Choosing a health care provider: the role of quality information. The Robert Wood Johnson Foundation Research Synthesis Report No. 14. Princeton, NJ: Robert Wood Johnson Foundation.

Harvey, L., Fowles, J. B., Xi, M., \& Terry, P. (2012). When activation changes, what else changes? The relationship between change in patient activation measure (PAM) and employees' health status and health behaviors. Patient Education and Counseling, 88, 338-343.

Hibbard, J. H. (2009). Using systematic measurement to target consumer activation strategies. Medical Care Research and Review, 66(Supp. 1), 9S-27S. PubMed http://dx.doi. org/10.1177/1077558708326969

Hibbard, J. H. \& Greene, J. (2013). What the evidence shows about patient activation: better health outcomes and care experiences; fewer data on costs. Health Affairs, 32(2), 207-214. 
Hibbard, J. H., Mahoney, E. R., Stockard, J., \& Tusler, M. (2005). Development and testing of a short form of the patient activation measure. Health Services Research, 40(6 Pt. 1), 1918-1930. PubMed http://dx.doi.org/10.1111/j.14756773.2005.00438.x

Klein, L. R., \& Ford, G. T. (2002). Consumer search for information in the digital age: An empirical study of pre-purchase search for automobiles. In Broniarczyk, S. M. and Nakamoto, K. (eds.), NA Advances in Consumer Research, 29, Valdosta, GA: Association for Consumer Research, 100-101.

Kolstad, J. T. \& Chernew, M. E. (2009). Quality and consumer decision making in the market for health insurance and health care services. Medical Care Research and Review, 66, 28S-52S.

Lee, Y.-Y., \& Lin, J. L. (2010). Do patient autonomy preferences matter? Linking patient-centered care to patient-physician relationships and health outcomes. Social Science \& Medicine, 71(10), 1811-1818. PubMed http://dx.doi. org/10.1016/j.socscimed.2010.08.008

Mehrotra, A., Hussey, P. S., Milstein, A., \& Hibbard, J. H. (2012). Consumers' and providers' responses to public cost reports, and how to raise the likelihood of achieving desired results. Health Affairs, 31(4), 843-851.

Millenson, M. L. (2011). Fixing the failure at physician compare. Kaiser Health News [accessed
January 27, 2011]. Retrieved from http:// www.kaiserhealthnews.org/columns/2011/ january/012711 millenson.aspx?referrer=search Scanlon, D. P., Beich, J., Alexander, J. A., Christianson, J. B., Hasnain-Wynia, R., McHugh, M. C., \& Mitler, J. N. (2012). The aligning forces for quality initiative: background and evolution from 2005 to 2012. The American Journal of Managed Care, 18(6), S115-S125. PubMed

Scanlon, D. P., \& Chernew, M. (1999). HEDIS measures and managed care enrollment. Medical Care Research and Review, 56(Supp. 2), 60-84. PubMed

Schneider, E. C. \& Epstein, A. M. (1998). Use of public performance reports: a survey of patients undergoing cardiac surgery. Journalof the American Medical Association, 279(20), 1638-1642.

Smith, M. A., Wright, A., Queram, C., \& Lamb, G. C. (2012). Public reporting helped drive quality improvement in outpatient diabetes care among Wisconsin physician groups. Health Affairs, 31(3), 570-577. PubMed http://dx.doi. org $/ 10.1377 /$ hlthaff.2011.0853

Stevens, B., \& Mittler, J. (2000). Making Medicare+Choice real: understanding and meeting the information needs of beneficiaries at the local level. Executive Summary. Washington, DC: Mathematica Policy Research, Inc. MPH Reference No. 8608-600. 